\title{
From the Editors: what makes a study sufficiently international?
}

\author{
Rosalie L Tung and \\ Arjen van Witteloostuijn ${ }^{*}$
}

\section{Area Editors}

Journal of International Business Studies (2008) 39, 180- 183.

doi: | 0. I057/palgrave.jibs.840035 |

\footnotetext{
*Although only this pair of names is printed with this letter, the opinions expressed here represent the collective view of the JBS Editorial Team, the Consulting Editors Board and the Editorial Review Board. We benefited much from extensive discussions with these three groups.
}

From the flow of submissions that arrive on the desk of the JIBS Editors, it appears that the issue of what makes a study sufficiently international to be of potential interest to JIBS and its readership is perhaps not so obvious to some contributors to the Journal. One of the top reasons for desk rejection is a misunderstanding by authors of JIBS's position on what studies are "sufficiently international". Some leading journals in the business and management domain (such as Academy of Management Journal $[A M J]$ ) consider studies to be sufficiently international if they either involve a non-US setting or a non-US co-author - this is definitely not the case in JIBS. In the following discussion, which includes specific examples, we clarify what makes a study sufficiently international for JIBS and provide advice to help authors to determine in advance the suitability of their potential submissions to JIBS.

As the leading journal in international business (IB, in short), JIBS entertains only submissions that are intrinsically international in nature. As noted in the JIBS Statement of Editorial Policy that can be found on http://www.palgrave-journals.com/jibs/jibs_ statement.html:

The domain of international business studies includes: the activities, strategies, structures and decision-making processes of multinational enterprises; interactions between multinational enterprises and other actors, organizations and institutions; the cross-border activities of firms (e.g., intra-firm trade, finance, investment, technology transfers, offshore services); how the international environment (e.g., cultural, political, economic) affects the activities, strategies, structures and decision-making processes of firms; comparative studies of businesses, business processes and organizational behavior in different countries and environments; and the international dimensions of organizational forms (e.g., strategic alliances, mergers and acquisitions) and activities (e.g., entrepreneurship, knowledge-based competition, corporate governance). (2nd paragraph)

Theories whose central propositions are distinctively international are encouraged, as are theories where both dependent and independent variables are international. Single-country studies are generally discouraged unless they are clearly situated within the domain of international business studies. (3rd paragraph)

Using this set of guidelines, certain studies are clearly inappropriate for JIBS. For one, data collected from outside the United States do not automatically qualify the study as international. In this regard, JIBS is clearly different from other journals that do not explicitly target IB studies. In their review of publications in $A M J$ in the past 30 years, Kirkman and Law (2005: 379) surmised that "the first five years of the 21st century can be regarded as a sort of 
golden age of international management research in $A M J^{\prime \prime}$. They used three criteria in their tabulation of what constitutes international management research: (a) a data set is from outside the United States, even if it involves a single-country sample; (b) the affiliation of one of the co-authors is nonUS; and (c) the subject is international in nature. Based on the JIBS Statement of Editorial Policy, the use of criteria (a) and (b) in determining what constitutes international management research is inappropriate from $J I B S^{\prime}$ 's perspective; only (c) is relevant (see also Tung, 2006). ${ }^{1}$

Note that we do not endorse blanket assertions that single-country studies, whether they are about or from the United States, or any other country, are inappropriate by definition. In general, singlecountry studies can be very valuable from the standpoint of understanding what is going on in a country. They are typically very informative and help us avoid pitfalls in doing business/ managing abroad. However, JIBS does not appear to be a suitable venue for studies of this nature if that were their sole focus. There are many top-tier outlets for high-quality single-country studies (see, e.g., Tsui, 2007, on this). For example, a study that looks at human resource management (HRM) practices of domestic firms in China does not fit the domain of JIBS. However, a comparative analysis of HRM practices in China with HRM practices in other transition economies in Central and Eastern Europe, to illustrate how changes in the institutional environment could affect HR practices, for example, would most likely qualify. Another example that would qualify is an analysis of the diffusion of HRM practices from European multinationals to domestic firms in China, or vice versa. Similarly, a comparative study of HRM practices in domestic firms and Chinese subunits of foreign multinational enterprises would also qualify.

Good comparative studies that explicitly compare different settings are still rare, even in JIBS. It is important to note that a comparative angle may be sufficient, but not necessarily so. Some would argue that a single-country study is sufficiently international if an explicit comparative discussion were included to reflect on how the findings for the focal country (say, HRM practices in China) relate to results reported in other studies on other countries (say, HRM practices in Central and Eastern Europe). If an author gathered data on HRM practices in China and drew on studies done by others on other transition economies to arrive at some general conclusions on HRM practices in transition economies and nothing more, however, this is very likely to result in a desk reject. ${ }^{2}$ The outcome will depend on the extent to which the authors can demonstrate convincingly that a well-accepted theory in the literature might not hold in China. In other words, if a paper can challenge or extend an existing paradigm by drawing upon the unique characteristics of a country, it might fit with JIBS. Of course, the assumption here is that the study is properly executed and can provide clear evidence that the findings of that research can improve the original theory.

What may render a single-country study suitable for JIBS is a new angle on IB theory. In other words, a study that extends beyond replication of one study in one national setting to a second study in another national setting to advance our understanding of some IB phenomenon would qualify. This can be done with or without explicit comparison with earlier findings for other countries.

Theory development is a necessary condition for JIBS, but JIBS is not dogmatic in what is considered to be theory development. ${ }^{3}$ The principal criteria for theory development are whether the theories are innovative and insightful in advancing IB. Since "cross-border" and "crosscultural" influences are very broad concepts, it is difficult to provide an exhaustive description of what studies meet or fail these criteria. Therefore, to shed some light on its meaning in JIBS's context, we provide some examples.

Take a study that develops hypotheses about emerging economy firms that are tested on firms in one country. If a paper merely treats theory as inherently universal and ignores the institutional or cultural differences across countries, the study does not meet JIBS's sufficiently international criterion, even if it were a multi-country study (Shenkar, 2001). However, a paper would qualify as international in nature if it linked the shared characteristics in a set of countries to IB theory, say firms in emerging markets in order to differentiate them from those in both developed and less developed economies. Furthermore, studies that check for universality rather than assume it at the outset also meet the sufficiently international requirement. The point is that the universality of theory cannot be taken for granted in an IB context. In other words, explicitly reflecting on contextualization of theory is a natural ingredient of IB.

Examples of single-country studies that would meet JIBS's sufficiently international criterion 
include, though, but are not limited to:

- entry modes of foreign firms into one host country;

- international and local strategies of multinational firms from one country;

- international regulations and how those impinge on domestic firms in one country;

- comparing MNEs from developed and emerging market economies, tested in the same country;

- comparing differences in business strategies, based on nationality of the firm, in the same country.

In the above-mentioned cases, while the data set only involves a single country, the central issues relate to cross-border or IB. Moreover, it is not only the issues that matter: in each and every case, the independent variables are "subscripted" by "country or market of origin" for (1) the entering mode firm, (2) the domicile of the MNE, (3) the origin of the regulations, and (4) and (5) the domicile of the firm, respectively. Hence, the issue is whether the independent or dependent variables are varied by something beyond national borders.

Thus, it is possible to perform research (i.e., collect data) on firms in a single country that fits with JIBS. In order for that to be the case, the research questions and hypotheses have to be firmly linked to IB such that a substantive contribution is made to extant IB knowledge. A minor or tangential linking of the findings of the study to IB in the Introduction and Discussion sections of the manuscript would not suffice. In other words, the data set can be from a single country, but the research question or questions have to be closely linked to IB. This does not exclude a focus on domestic units of analysis (e.g., the structure or strategy of local enterprises), but the analyses have to be explicitly comparative or centered in the international environment of business or about cross-border activities.

Another example that may help clarify this argument further pertains to a study of the attitudes of immigrants from different parts of the world, now all located in one country, toward facilitating trade and investment in their respective countries of origin. A study of this nature is acceptable only if the subjects are managers who are in a position to make trade and investment decisions - not if they are international students or citizens not engaged in IB since their attitudes will not be closely linked to IB. Similarly, a study that merely focuses on immigrant start-ups in their current country of residency does not meet the international criterion. However, a study on how home-country (i.e., country of origin) linkages influence immigrant businesses in their country of residency, or vice versa, would most likely fit.

As noted earlier, since the topics and themes that meet the cross-border and cross-cultural criteria are so broad and wide-ranging, it is clearly impossible to provide a comprehensive listing of what studies are acceptable or not to JIBS. Some judgment call will always be involved. In the final analysis, JIBS seeks to publish papers that are intrinsically international in nature, which are clearly embedded in the IB literature, ${ }^{4}$ and which offer new and exciting insights in IB. These studies may be based on single or multiple countries, but the key is that they must have cross-border and cross-cultural implications that generate new advances and developments in IB research. And indeed, as each issue of JIBS makes clear, there is much exciting work being done in IB.

\section{Notes}

${ }^{1}$ Even if one were to accept Kirkman and Law's criterion (b), applying it will turn out to be problematic. This is so because the growing mobility of academics around the world implies that the sheer fact that one's affiliation is outside of the US does not render the study "international". Moreover, Tung (2006) referred to several developments that may further complicate the criteria (a) and (b) used in the Kirkman and Law (2005) article: (i) the growing participation of non-North Americans in traditionally North American professional associations; (ii) the "bandwagon" effect, such as the expanding cooperation between North American researchers and peers in other countries for purposes of data collection involving non-US samples, and holding major conferences outside of the US; and (iii) increasing emphasis on research in other than North American business schools. While these are all positive developments, it does not follow that all of these studies qualify as IB research.

${ }^{2}$ This implies that, generally speaking, JIBS is not interested in mere replication studies in other singlecountry settings. There should be more to it, as explained in the main text. Of course, replication studies are absolutely essential to advance from context-specific to general international knowledge (Meyer, 2007). However, it is beyond the scope of this letter to delve into the merits and limitations of replication studies.

${ }^{3}$ This criterion is also in line with the revised 2004 domain statement for the International Management Division of the Academy of Management, which "focuses on content pertaining to the theory, research, 
and practice of management with a cross-border or cross-cultural dimension" (Revised 8 August 2004, http://aomonline.org).

${ }^{4} \mathrm{~A}$ surprisingly large number of submissions to JIBS are without a single reference to a JIBS article, or even

\section{References}

Kirkman, B.L. \& Law, K.S. 2005. International management research in $A M$ ): Our past, present, and future, Academy of Management Journal, 48(3): 377-386.

Meyer, K. 2007. Contextualising organizational learning: Lyles and Salk in the context of their research, Journal of International Business Studies, 38(1): 27-37.

Shenkar, O. 2001. Cultural distance revisited: Towards a more rigorous conceptualization and measurement of cultural differences, Journal of International Business Studies, 32(3): $519-535$.

Tsui, A.S. 2007. From homogenization to pluralism: International management research in the Academy of Management and beyond, Academy of Management Journal, 50(6): 1353-1364.

Tung, R.L. 2006. North American research agenda and methodologies: Past imperfect, future - limitless possibilities, Asian Business and Management, 5(1): 23-35.

\section{ABOUT THE AUTHORS}

Rosalie L Tung is a chaired Professor of International Business at Simon Fraser University. She is without any reference to an IB paper. Also, many of such papers do not reflect at all on IB issues, let alone their contribution to the extant IB literature. It goes without saying that such submissions are clear candidates for desk rejects.

a past President of the Academy of Management. Her research interests are in strategic international human resource management and comparative management. She was born in China, received her $\mathrm{PhD}$ from the University of British Columbia, and is a dual citizen of the US and Canada (email: tung@ sfu.ca).

Arjen van Witteloostuijn is the JIBS Area Editor for Economics, Ecology, and Strategy in International Business. He is Research Professor of Economics and Management at the University of Antwerp (email: arjen.vanwitteloostuijn@ua.ac.be). 